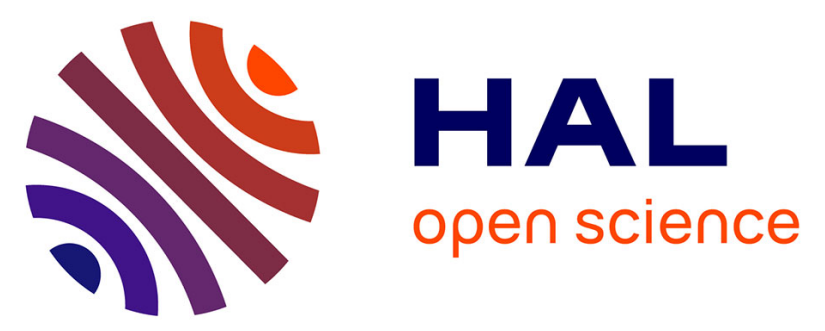

\title{
Influence of environmental parameters on the photocatalytic oxidation efficiency of acrylonitrile and isoflurane; two operating room pollutants
} Henrietta Essie Whyte, Cécile Raillard, Albert Subrenat, Valérie Hequet

\section{- To cite this version:}

Henrietta Essie Whyte, Cécile Raillard, Albert Subrenat, Valérie Hequet. Influence of environmental parameters on the photocatalytic oxidation efficiency of acrylonitrile and isoflurane; two operating room pollutants. Building and Environment, 2019, 154, pp.97-106. 10.1016/j.buildenv.2019.03.014 . hal-02285131

\section{HAL Id: hal-02285131 \\ https://hal.science/hal-02285131}

Submitted on 12 Sep 2019

HAL is a multi-disciplinary open access archive for the deposit and dissemination of scientific research documents, whether they are published or not. The documents may come from teaching and research institutions in France or abroad, or from public or private research centers.
L'archive ouverte pluridisciplinaire HAL, est destinée au dépôt et à la diffusion de documents scientifiques de niveau recherche, publiés ou non, émanant des établissements d'enseignement et de recherche français ou étrangers, des laboratoires publics ou privés. 


\title{
Influence of environmental parameters on the photocatalytic oxidation efficiency of acrylonitrile and isoflurane; two operating room pollutants
}

\author{
Henrietta Essie Whyte*, Cécile Raillard, Albert Subrenat, Valérie Héquet \\ IMT Atlantique, GEPEA UMR CNRS 6144, 4 Rue Alfred Kastler CS 20722, 44307, Nantes Cedex 3, France
}

Keywords:

PCO

Operating rooms

Acrylonitrile

Isoflurane

Single-pass removal efficiency

Induction time

\begin{abstract}
A B S T R A C T
In hospitals, operating rooms (ORs) are very demanding in terms of the indoor air quality (IAQ) and require systems that minimize the concentrations of pollutants (microorganisms, chemical and particulate matter). Air treatment devices that use photocatalytic oxidation (PCO) could potentially be used in the OR to improve IAQ. In this work, the fate of two OR pollutants acrylonitrile (chemical found in surgical smoke) and isoflurane (anesthetic gas) when they go through a PCO device was investigated. The experiments were conducted in a laboratory closed loop multi-pass reactor. A mathematical model was utilized to enable the calculation of one indicator (single-pass removal efficiency) for acrylonitrile and two indicators (induction period and single-pass removal efficiency) for isoflurane. The degradation efficiency was then accessed by studying the influence of environmental parameters on these indicators. The parameters that were studied are the relative humidity, presence of co-pollutants and presence of particles. The parameters were observed to have similar effects on the degradation of both compounds. Increasing relative humidity inhibited the degradation probably due to competitive adsorption. The presence of co-pollutants like nitrous oxide and acetic acid caused a possible competition for adsorption unto active sites thus decreased the degradation efficiency of acrylonitrile and isoflurane. The increase in the concentration of the co-pollutants enhances the competitive effect and further decreases the degradation efficiency of the target pollutants. Finally the presence of particles on the photocatalytic media could block active sites thereby inhibiting the degradation of acrylonitrile and isoflurane.
\end{abstract}

\section{Introduction}

The hospital is a more complex environment than that of residential and commercial buildings. There are several zones where specific activities are performed and thus, occupants (hospitals workers, patients, etc) are exposed to different chemical pollutants [1,2]. Another factor adding to the complexity of hospitals is the fact that the different zones have various indoor air quality (IAQ) requirements. In the hospital, the operating room (OR) is one of the most demanding areas when it comes to the IAQ and requires careful control of its environment to minimize pollutant levels [3]. The indoor air of an operating room is polluted by different chemical pollutants like waste medical gases used for anesthesia, disinfection and sterilizing substances and surgical smoke [3-5]. The two main culprits however are waste anesthetic gases and chemicals present in surgical smoke. The presence of these substances is known to have adverse health effects on and can lead to discomfort of OR personnel thus, personnel exposure should be limited [4].

Isoflurane is one of the most commonly used anesthetic gases worldwide and it is normally present in the air through leaks in the patient breathing circuit, during installation and disconnection of the system and also when patient exhales. Studies have demonstrated that chronic exposure to isoflurane can cause liver and kidney diseases, irritation of skin, eyes, mouth and throat and can also increase the risks of spontaneous abortion and congenital abnormalities [6-10]. The occupational exposure limits (OEL) for an 8-h time weighted average set by NIOSH is $2 \mathrm{ppm}$ without concomitant $\mathrm{N}_{2} \mathrm{O}$ exposure and $0.5 \mathrm{ppm}$ with concomitant $\mathrm{N}_{2} \mathrm{O}$ exposure. Surgical smoke is produced during electro, laser or ultrasonic surgery to cut, coagulate, desiccate, fulgurate, or vaporize tissues. It is known to consist of $95 \%$ water vapor and $5 \%$ blood and particulate matter (tissue particles, viruses and bacteria) and chemical compounds [11]. Surgeons and operating theatre staff are routinely exposed to pollution from the surgical smoke. It hinders the vision of the surgeon, produces an unpleasant odor, and releases harmful substances into the air that are harmful to the health of the staff [11]. The chemicals present in greatest quantity in surgical smoke are hydrocarbons and nitrile compounds among which is acrylonitrile a hazardous compound of concern. Short-term exposure to acrylonitrile can cause eye irritation, nausea, vomiting, headache, sneezing, 
weakness and light headedness, whilst long-term exposure may cause cancer $[12,13]$. The occupational exposure limit (OEL) for an 8-h time weighted average set by NIOSH is $2 \mathrm{ppm}$. The concentrations of these pollutants found in the OR is limited and in the literature the concentrations of isoflurane and acrylonitrile can range from 0.01 to 15 ppm [4,5,14-16].

In ORs, occupants' health and comfort is mostly ensured by heating, ventilating and air conditioning (HVAC) systems through the dilution of indoor air pollutant concentrations by the supply of conditioned outdoor air [3]. Desirable conditions are met by adhering to a ventilation rate. In the United States of America, ASHRAE [17] recommends a minimum of 20 Air Change per Hour (ACH) whilst the standard NFS 90-351 for France recommends the minimum to be 25 ACH [18]. The higher the ventilation rate, the better the dilution effect. However, higher rates result in increased energy consumption necessary to condition (heating, cooling, humidification and dehumidification) the air. It may also supply pollutants from outdoors [19]. In addition, filters installed in typical HVACs are targeted for particulate matter and bioaerosols control and as such not very efficient at removing some indoor chemical pollutants [20]. Therefore, implementation of air treatment technologies whether as standalone or as part of the existing HVAC system (in-duct), is becoming popular as a complementary means of improving IAQ. These technologies control chemical pollutants and allow air quality levels to be maintained with reduced outdoor air supply and concomitant energy savings [21-25]. Technologies for removing VOC contaminants include ozonation, cold plasma, and photocatalytic oxidation (PCO). Among the different air cleaning technologies used for the removal of these pollutants, photocatalytic oxidation seems to be more and more employed.

PCO has been studied for several decades and is a cheap, energy efficient solution for air treatment [26,27]. It removes gaseous contaminants via chemical reactions on semiconductor (mostly $\mathrm{TiO}_{2}$ ) catalyst surface under UV irradiation. It has the advantage of being a flexible solution for the degradation of a wide spectrum of gaseous pollutants [28-32]. Over the years most of the studies have been performed on common home, office and school pollutants like formaldehyde, toluene, benzene whilst little or no attention is paid to the degradation of specific hospital pollutants. The performance of PCO is influenced by several factors that can be categorized in two types; process parameters (eg. air velocity, light intensity) and environmental parameters (e.g initial concentration, relative humidity, and presence of co-pollutants). The influence of these key parameters has been greatly studied in the literature [33-40]. Air treatment devices that use PCO could potentially be used in ORs thus the fate of gaseous OR pollutants when they go through the PCO device should also be studied.

This work for the first time investigates the performance of a PCO system in removing isoflurane and acrylonitrile, two compounds present in the OR indoor air with the objective of studying the influence of three environmental parameters, relative humidity, presence of copollutants and presence of particles on their degradation under conditions that are relevant to actual applications. The experiments were conducted in a closed loop reactor which has been designed to study low concentration air pollutants and has also been recently modeled $[41,42]$. This reactor also permits a better representation of PCO systems functioning in dynamic mode and is realistic regarding air treatment systems working as standalone devices or implanted in HVAC systems.

\section{Materials and methods}

\subsection{Experimental set-up}

The experimental set-up used in this study is presented in Fig. 1. It consists of the VOC generation bench, the photocatalytic reactor and the sampling and analytical devices.

\subsubsection{Generation of pollutant concentrations}

To generate the desired concentrations of the pollutants, the process started first by generating clean humid air. To do this, compressed air from the laboratory network was passed through an air zero generator Claind AZ 2020 to remove organic gaseous compounds and then through a Pressure swing Adsorption (PSA) device to remove humidity and $\mathrm{CO}_{2}$. The air was then humidified to a desired level by bubbling it through a water bottle at an average room temperature of $20^{\circ} \mathrm{C}$. Then the pollutants were mixed with the humid air zero to dilute them before injection into the reactor. Acrylonitrile $\left(\mathrm{C}_{3} \mathrm{H}_{3} \mathrm{~N}\right)$ was supplied by Air products whilst isoflurane $\left(\mathrm{C}_{3} \mathrm{H}_{2} \mathrm{ClF}_{5} \mathrm{O}\right)$ was supplied by Linde Gas. Nitrous oxide $\left(\mathrm{N}_{2} \mathrm{O}\right)$ was supplied by Air Liquide. The pollutants were supplied in certified commercial gas cylinder balanced in nitrogen at 150 bars. Finally, the desired concentrations were achieved by adjusting the gas flow rates using mass flow controllers (MFC). For acetic acid, it was injected into the reactor as a vapor by means of a $10 \mathrm{~mL}$ airtight syringe into the tranquilization chamber. The vapors were prepared by evaporating liquid acetic acid $(99.95 \%$ from Sigma Aldrich) in a $285 \mathrm{~mL}$ pyrex glass bulb under vacuum.

\subsubsection{Photocatalytic reactor}

The reactor that was used to perform experiments is a 420-L multipass reactor that has been described in previous articles [43-46]. It is a closed-loop reactor made up entirely of stainless steel to minimize surface losses of pollutants. The reactor includes a photocatalytic module containing a plane geometry photocatalytic media and two 18W UVC lamps (Phillips TUV PL-L series), a variable speed fan and a tranquilization chamber. The air stream flowing through the reactor is controlled by the fan. For the present study, the flow was set at 148 $\mathrm{Nm}^{3} \mathrm{~h}^{-1}$. The studied compounds are introduced and sampled through tranquilization chamber which has a honeycomb placed at its inlet to provide a homogeneous flow distribution.

Leak tests were performed prior to degradation experiments at several flow rates and were estimated to range from 0.1 to $2.3 \%$ per hour when flow rates increased from 73 to $216 \mathrm{Nm}^{3} \mathrm{~h}^{-1}$ respectively. Preliminary experiments were also carried out to evaluate the extent of adsorption and photolysis processes on pollutant removal. The removal rates for adsorption and photolysis were calculated at 0.1 and $0.3 \%$ per hour respectively indicating that no significant loss of pollutants was observed under UV light without the media or when exposed to the media without UV light.

A Quartzel ${ }^{\infty}$ photocatalytic media was used in this work. It is a commercial media produced by Saint-Gobain Quartz made up of $\mathrm{SiO}_{2}$ fibers coated with $\mathrm{TiO}_{2}$ deposited through a sol-gel method and pressed into a felt. The media has an average thickness of $17.5 \pm 1.5 \mathrm{~mm}$, a developed surface of $0.04 \mathrm{~m}^{2}(20 \mathrm{~cm} \times 20 \mathrm{~cm})$ and a $\mathrm{TiO}_{2}$ load of $94 \mathrm{~g} \mathrm{~m}^{-2}$. A Micrometrics ASAP 2020 device using $\mathrm{N}_{2}$ adsorption measured the BET specific surface area as $112 \pm 1 \mathrm{~m}^{2} \mathrm{~g}^{-1}$ with a Micrometrics ASAP 2020 by $\mathrm{N}_{2}$ adsorption. A JOEL JSM 5800LV Scanning Electron microscope (SEM) was used to analyze the surface of the media. The results (Fig. $2 \mathrm{a}$ and $\mathrm{b}$ ) showed that the coated fibers are long and interconnected and form a complex mesh. This complexity offers a tortuous path for air flow and increases the probability of pollutants to be trapped and degraded. The SEM image (Fig. 2 b) shows the variation in thickness of the coated fibers. The fiber thickness was estimated to be in the range $10 \mu \mathrm{m}-20 \mu \mathrm{m}$.

\subsubsection{Sampling and analytical methods}

To monitor the pollutant concentrations over the period of the degradation, samples were taken onto stainless-steel catridges packed with Carbopack B (Perkin Elmer). The Automatic Clean Room Sampling System (ACROSS) by Tera Environnement was used to sample at a rate of $200 \mathrm{~mL} \mathrm{~min}^{-1}$ for $2.5 \mathrm{~min}$. The analysis was carried out using a Thermal Desorber/Gas Chromatograph/Flame Ionization Detector/ Mass Spectrometer (TD/GC/FID/MS). The column used in the GC was a polar column from Restek (Rxi-624Sil MS) which was connected to a 


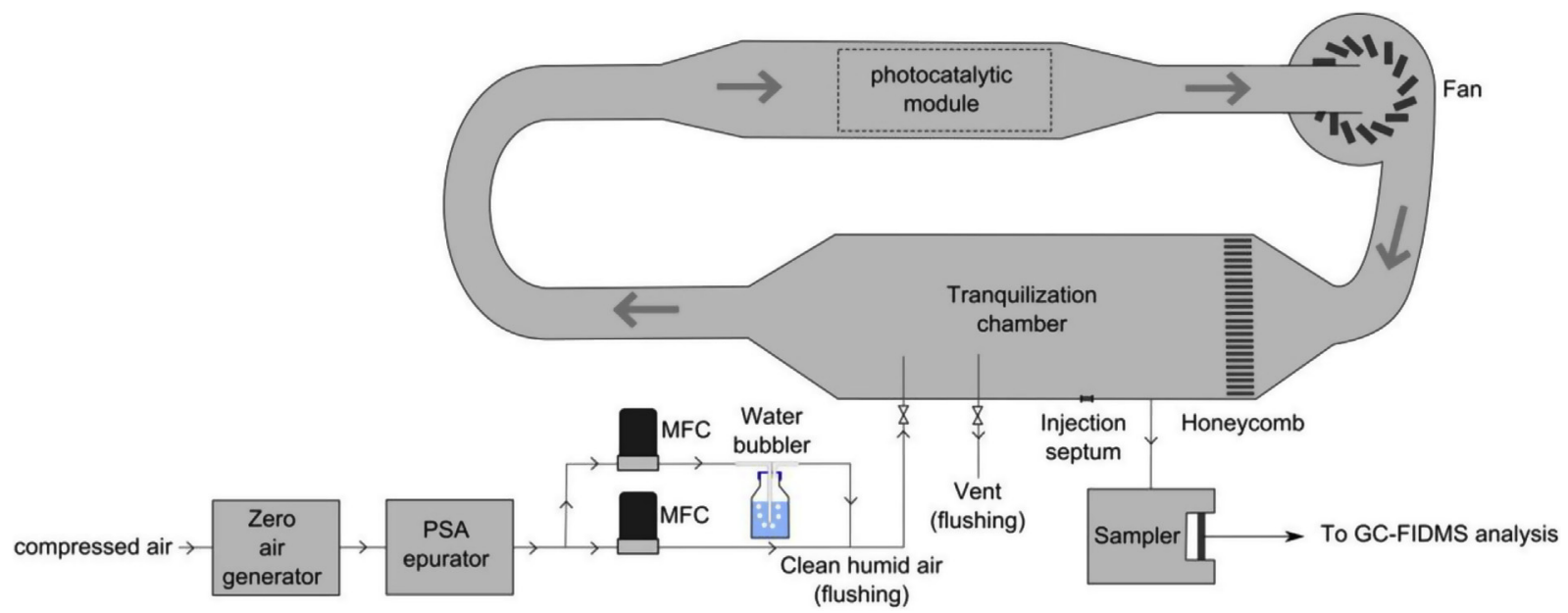

Fig. 1. Schematic representation of the closed-loop photocatalytic reactor.

FID for the quantification of compounds and a MS for the identification of compounds. The TD/GC/FID/MS analysis conditions are described in Table 1.

\subsection{Particle loading of photocatalytic media}

The effect that the presence of particles may have on the photocatalytic degradation efficiency was studied by clogging the media surface with micronized rice. The micronized rice particles were chosen to simulate the presence of particles. The particle diameter range was $0.25-10.5 \mu \mathrm{m}$ thus was a good representation of particles that could be collected on the photocatalytic media in an OR as for example surgical smoke is known to contain particles with diameters ranging from 0.35 to $6.5 \mu \mathrm{m}$ [47]. The generated particles were first oven-dried overnight at $50^{\circ} \mathrm{C}$. A Palas RBG 1000 particle generator was used to load the rice particles onto the photocatalytic media. A generation time of about $45 \mathrm{~min}$ allowed a loading rate of $0.002 \mathrm{~g} \mathrm{~m}^{-2}$.

\subsection{Calculating performance indicators}

In order to evaluate the influence of the parameters on the degradation of isoflurane and acrylonitrile, quantitative indicators were needed. Before the indicators are discussed, a brief presentation of the degradation profiles of acrylonitrile and isoflurane are presented.

Fig. 3 shows the degradation profile of acrylonitrile. Under the chosen reference experimental conditions of $C_{O}=2 \mathrm{ppm}, v=1 \mathrm{~m} \mathrm{~s}^{-1}$ and $I=4.5 \mathrm{~mW} \mathrm{~m}^{-2}$, the complete degradation of acrylonitrile was achieved in $1 \mathrm{~h}$. The degradation profile is characterized by a mono- exponential decay curve which is representative of an apparent first order decay. By fitting the experimental points to the mono-exponential equation $\left[C / C_{o}=\exp \left(-\mathrm{k}_{\mathrm{app}} t\right)\right]$, the model fit almost perfectly to the experimental points as indicated by coefficient of determination $\left(\mathrm{R}^{2}=0.98\right)$ in Table 2 .

The reference experiments were performed three times to access the repeatability. The calculation of the first order constants $\left(\mathrm{k}_{\mathrm{app}}\right)$ calculated from the mono-exponential equation were quite similar (Table 2) indicating the repeatability of the experiments.

Fig. 4 shows the degradation profile of isoflurane. Under the experimental conditions $C_{O}=0.5 \mathrm{ppm}, v=1 \mathrm{~m} \mathrm{~s}^{-1}, I=4.5 \mathrm{~mW} \mathrm{~cm}^{-2}$, it can also be seen that the degradation curve can be divided into two distinct phases: the first phase where degradation occurs slowly and a second phase where the degradation accelerates. This degradation behavior of isoflurane was similar to what some authors have described in the literature for another chlorinated compound trichloroethylene. The authors state that trichloroethylene undergoes a reaction mechanism that involves $\mathrm{OH}^{\circ}$ and $\mathrm{Cl}^{\circ}$ [48-51]. $\mathrm{OH}^{\circ}$ first attacks TCE to generate $\mathrm{Cl}^{\circ}$. The $\mathrm{Cl}^{\circ}$ then attack trichloroethylene and ensure the continous attack of TCE by propagating a chain reaction. This propagation plays a key role in increasing the degradation rate of TCE. Based on this, a hypothesis is therefore made that isoflurane may probaly undergo a reaction mechanism similar to that of tricholorethylene. In that, the first phase could probably correspond to $\mathrm{OH}^{\circ}$ reactions with isoflurane to generate $\mathrm{Cl}^{\circ}$. The second phase could probably be attributed to $\mathrm{Cl}^{\circ}$ reactions with isoflurane leading to a possible chain propagation reaction.

The reference experiment was also carried out at regular intervals to ascertain the repeatability of the experiments. The results are shown to
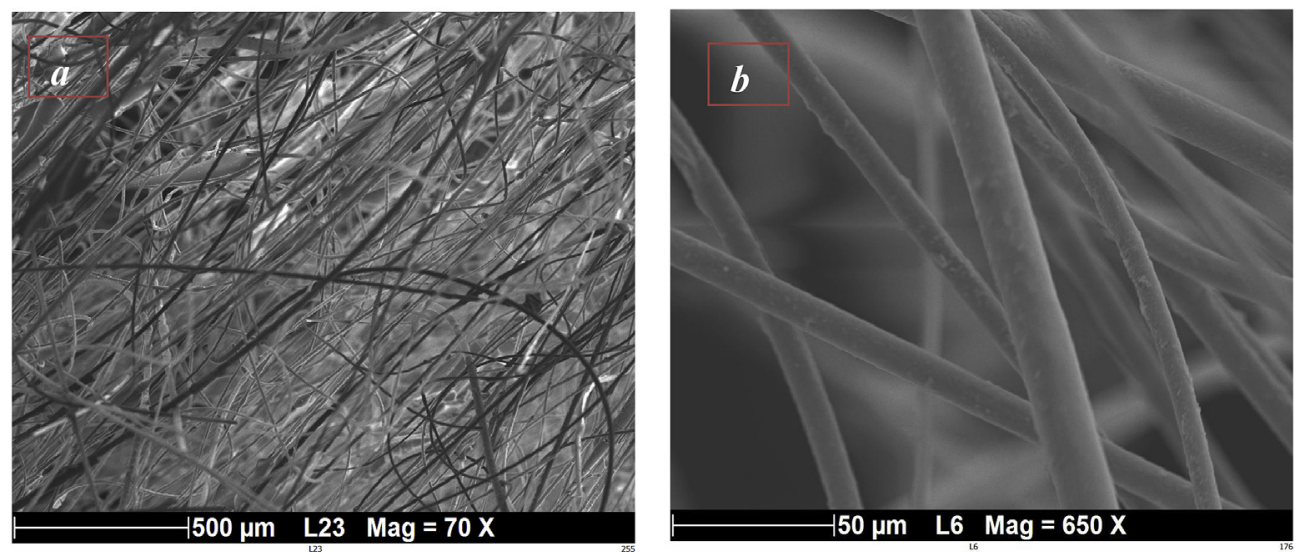

Fig. 2. SEM images of PCO media - (a) x 70, (b) x 650 . 
Table 1

TD/GC/FID/MS analysis conditions.

\begin{tabular}{|c|c|c|}
\hline Step & Parameter & Value \\
\hline Tube desorption & $\begin{array}{l}\text { Desorption temperature } \\
\text { Desorption time }\end{array}$ & $\begin{array}{l}250^{\circ} \mathrm{C} \\
10 \mathrm{~min}\end{array}$ \\
\hline Trap desorption & $\begin{array}{l}\text { Focusing trap temperature } \\
\text { Desorption temperature } \\
\text { Transfer line temperature }\end{array}$ & $\begin{array}{l}-30^{\circ} \mathrm{C} \\
250{ }^{\circ} \mathrm{C} \\
250{ }^{\circ} \mathrm{C}\end{array}$ \\
\hline FID & $\begin{array}{l}\text { Temperature }\left({ }^{\circ} \mathrm{C}\right) \\
\text { Fuel } \\
\text { Flow rate }\left(\mathrm{mL} \cdot \mathrm{min}^{-1}\right) \\
\text { Oxidizer } \\
\text { Flow rate }\left(\mathrm{mL} \cdot \mathrm{min}^{-1}\right)\end{array}$ & $\begin{array}{l}250 \\
\mathrm{H}_{2} \\
45 \\
\text { Air } \\
450\end{array}$ \\
\hline MS detection & $\begin{array}{l}\text { Source temperature }\left({ }^{\circ} \mathrm{C}\right) \\
\text { Electron Energy }(\mathrm{eV}) \\
\text { Scan range }(\mathrm{m} / \mathrm{z})\end{array}$ & $\begin{array}{l}200 \\
70 \\
20-200\end{array}$ \\
\hline GC & $\begin{array}{l}\text { Column } \\
\text { Oven temperature program }\end{array}$ & $\begin{array}{l}\text { Rxi-624SilMS }(60 \mathrm{~m} \times 0.35 \mathrm{~mm} \times 1.8 \mu \mathrm{m}) \\
35^{\circ} \mathrm{C}(5 \mathrm{~min}), 15^{\circ} \mathrm{C} \cdot \mathrm{min}^{-1} \text { to } 150^{\circ} \mathrm{C}(2 \mathrm{~min}), 20^{\circ} \mathrm{C} \cdot \mathrm{min}^{-1} \text { to } 250^{\circ} \mathrm{C}(5 \mathrm{~min})\end{array}$ \\
\hline
\end{tabular}

The limits of detection was calculated by multiplying the background noise by 3 . It was calculated as 0.1 ppm for isoflurane and 0.075 ppm for acrylonitrile.

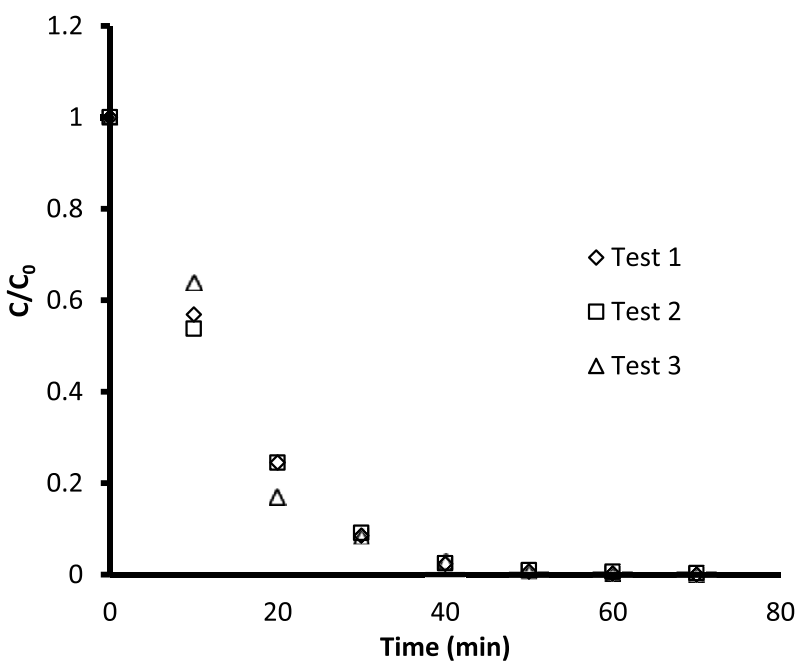

Fig. 3. Degradation profile of acrylonitrile under the reference experimental conditions of $C_{O}=2 \mathrm{ppm} ; v=1 \mathrm{~m} \mathrm{~s}^{-1} ; I=4.5 \mathrm{~mW} \mathrm{~cm}^{-2} ; R H=50 \%$.

Table 2

First order constants and coefficient of determination calculated from first order equation for the three references acrylonitrile experiments $\left(C_{O}=2 \mathrm{ppm}\right.$; $v=1 \mathrm{~m} \mathrm{~s}^{-1} ; I=4.5 \mathrm{~mW} \mathrm{~cm}^{-2} ; R H=50 \%$ ).

\begin{tabular}{lll}
\hline Test & $\mathrm{k}_{\text {app }}\left(\mathrm{min}^{-1}\right)$ & $\mathrm{R}^{2}$ \\
\hline 1 & 0.0954 & 0.98 \\
2 & 0.0960 & 0.98 \\
3 & 0.0956 & 0.98 \\
Average \pm Std & $0.0957 \pm 0.0003$ & \\
\hline
\end{tabular}

\section{be repeatable (Fig. 4).}

Based on the degradation mechanisms, one indicator, the singlepass removal efficiency was chosen for acrylonitrile whilst two indicators, the single pass removal efficiency and the induction period (duration of the first phase), were chosen for isoflurane.

As previously mentioned, the reactor used in this work is a multi pass reactor. This reactor is well adapted to provide information on the decay profiles but does not provide direct information on the singlepass removal efficiency. This indicator has to be determined indirectly by employing mathematical models. In this work the model that is used has been developed by Dumont and Héquet and is explained elsewhere

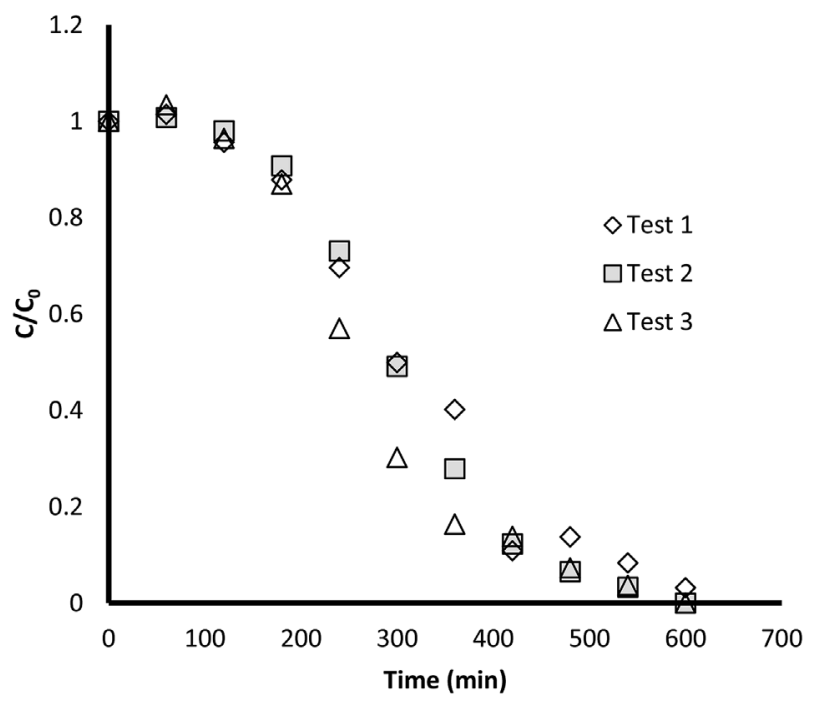

Fig. 4. Degradation profile of isoflurane under the reference experimental conditions of $C_{O}=0.5 \mathrm{ppm} ; v=1 \mathrm{~m} \mathrm{~s}^{-1} ; I=4.5 \mathrm{~mW} \mathrm{~cm}^{-2} ; R H=50 \%$.

[41]. The model, which describes the first order decay relationship of concentration vs. time in a closed-loop reactor is given as follows:

$\mathrm{C}=C_{0} \exp \left\{-\frac{t}{\tau_{R}}[1-\exp (-\alpha)]\right\}$

In Eq. (1) the term $\alpha$ is the single-pass removal efficiency and represents the fraction of the total flow treated during the time $\tau_{R}$ (residence time in the reactor). $C$ is the pollutant concentration at time $t$ and $C_{O}$ is the initial pollutant concentration. Numerical resolutions were carried out using Excel $^{\circledR}$ Solver which is based on the least-square method.

Fig. 5 shows acrylonitrile degradation experimental points fitted to the model (Eq. (1)). The model is shown to fit the experimental points satisfactorily based on the regression co-efficient $\left(\mathrm{R}^{2}\right)$ of 0.99 . Under these conditions, the single-pass removal efficiency $(\boldsymbol{\alpha})$ was then calculated as 0.012 . This indicated that in one pass, $1.2 \%$ of acrylonitrile would be eliminated from the total flow that passed through the media.

Fig. 6 shows the isoflurane experimental concentration decay curve fitted to the model (Eq. (1)). It can be observed for irradiation time from $\mathrm{t}=0$ to $\mathrm{t}=130 \mathrm{~min}$ that the experimental points are not well 


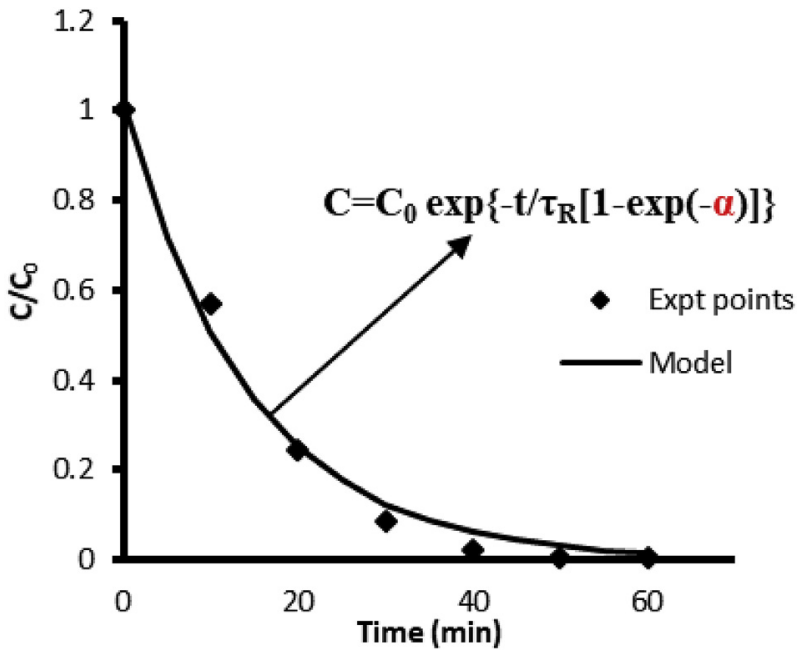

Fig. 5. Experimental degradation curve of acrylonitrile fitted to model under reference experimental conditions of $C_{o}=2 \mathrm{ppm} ; \quad v=1 \mathrm{~m} \mathrm{~s}^{-1}$; $I=4.5 \mathrm{~mW} \mathrm{~cm}^{-2}[52]$.

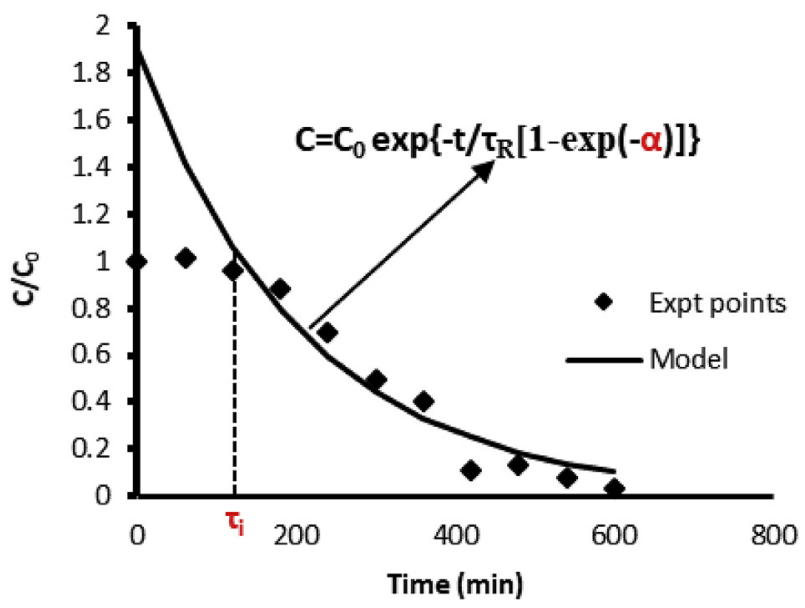

Fig. 6. Experimental degradation curve of isoflurane fitted to model enabling calculation of two indicators $\alpha$ and $\tau_{\mathrm{i}}$ under reference experimental conditions of $C_{o}=0.5 \mathrm{ppm} ; v=1 \mathrm{~m} \mathrm{~s}^{-1} ; I=4.5 \mathrm{~mW} \mathrm{~cm}^{-2}$ [46].

explained by the model, but from $t=130$ min the model describes the experimental values quite satisfactorily $\left(R^{2}=0.94\right)$. By modeling the second phase with the Dumont and Héquet model it was possible to determine the induction period $\left(\tau_{\mathrm{i}}\right)$ as $130 \mathrm{~min}$ and calculate the $\alpha$ for the second phase as $8.22 .10^{-4}$.

To be able to study the influence of the parameters on the performance indicator, the parameter of interest was varied whilst all others were kept constant. Due to the duration of each experiment and the number of experiments that needed to be done, the coefficient of variation on the performance indicators for the reference experiments was calculated and reported for all the set of experiments. The coefficient of variation on the reference experiment was calculated as follows:

$\delta=\frac{\sigma}{\bar{x}} * 100$

Where $\delta$ is the coefficient of variation, $\sigma$ is the standard deviation and $\bar{x}$ is the average value of the performance indicator calculated from the three reference experiments. The coefficient of variation calculated on $\alpha$ for the acrylonitrile experiments based on the mean and standard deviation of the thrice repeated reference experiment was calculated as $1 \%$. Whilst the coefficient of variation on $\alpha$ and $\tau_{\mathrm{i}}$ was calculated as $9 \%$ and $5 \%$ respectively for isoflurane experiments based on the repetition of the reference experiment.

\section{Results and discussion}

\subsection{Relative humidity $(\mathrm{RH})$}

In ORs, the humidity levels as recommended by national guidelines such as NFS 90-351 [18] and ASHRAE 170-2017 [17] for France and the US respectively is $30-60 \%$. However levels measured could be outside this range. Wong et al. [3] measured levels of $80 \%$ in a Malaysian OR. As a result of this, in the present study, the influence of $\mathrm{RH}$ on the degradation process of the two target compounds were studied from $20 \%$ to $80 \%$ at $20{ }^{\circ} \mathrm{C}$ which gave moisture content of 4657-18893 ppm. This would provide representative information on how different RH levels encountered in the ORs affect the performance of PCO during the degradation of isoflurane and acrylonitrile.

In the literature, the role of water vapor in the photocatalytic oxidation process has been described as a dual one [53-56]. On one hand adsorbed water molecules are oxidized into $\mathrm{OH}^{\circ}$ which are necessary for the progress of the reaction whilst on the other hand excessive amounts of water creates a competition with the pollutants for adsorption onto active sites which inhibits the degradation. When varying humidity, some studies have shown that both effects can occur depending on the humidity range studied whilst other studies have reported that only one of these effects is visible. For example, Mo et al. [57] studied the influence of relative humidity $(\mathrm{RH})$ in a range of $0-70 \%$ on the degradation of toluene $(0.7 \mathrm{ppm})$. They showed that the removal efficiency of toluene increased for $\mathrm{RH}$ ranging from 0 to $35 \%$ due to the promotion of the degradation by the formation of $\mathrm{OH}^{\circ}$ and decreased for $\mathrm{RH}$ from $35 \%$ to $70 \%$ as a result of competitive adsorption between the toluene molecules and the water molecules.

For the acrylonitrile experiments, velocity and light intensity were fixed at $1 \mathrm{~m} \mathrm{~s}^{-1}$ and $4.5 \mathrm{~mW} \mathrm{~cm}{ }^{-2}$ respectively whilst initial concentration was maintained at $2 \mathrm{ppm}$. Fig. 7 shows the influence of $\mathrm{RH}$ on acrylonitrile degradation. It can be observed that the single-pass removal efficiency decreases when the RH is increased from $20 \%$ to $80 \%$.

The results for the influence of $\mathrm{RH}$ on the degradation of isoflurane are shown in Fig. 8. The results of the experimental study show that as the relative humidity is increased from $20 \%$ to $80 \%$; (i) isoflurane induction periods are increased; (ii) the single-pass removal efficiency is decreased.

The results from this study show that increasing the relative humidity decreases the degradation efficiency of both compounds. This observation can be interpreted as the competition for adsorption between the pollutants and water molecules. As the amount of water molecules increases, they occupy the active sites which in turn decreases the chance the pollutants have to react with the active species

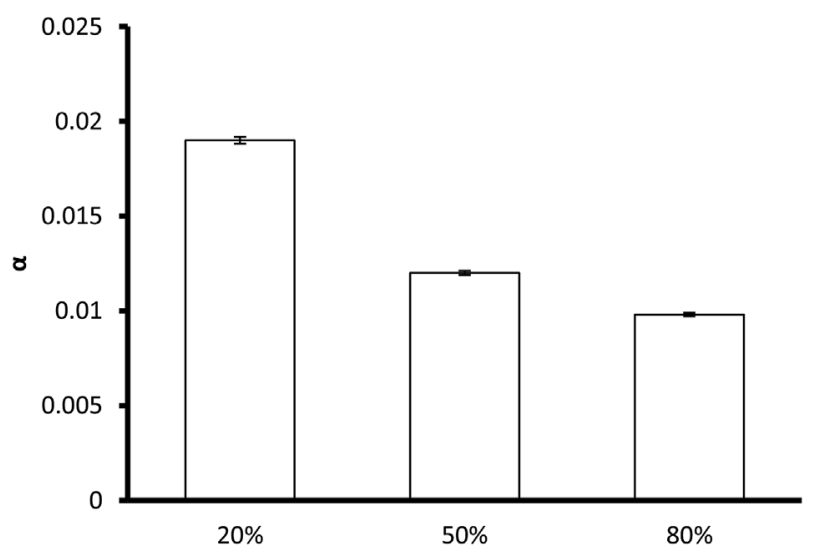

Fig. 7. Influence of relative humidity on the single-pass removal efficiency determined during acrylonitrile degradation. ( $C_{0}=2 \mathrm{ppm} ; v=1 \mathrm{~m} \mathrm{~s}^{-1}$; $I=4.5 \mathrm{~mW} \mathrm{~cm}^{-2}$ ). 

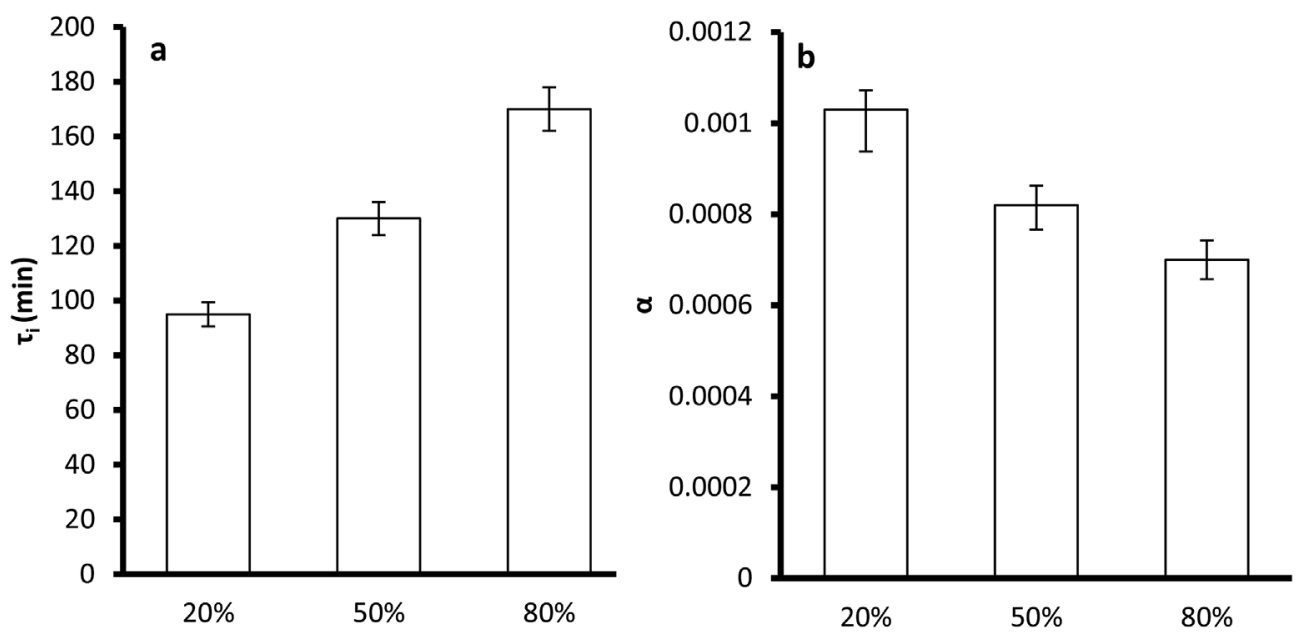

Fig. 8. Influence of relative humidity on (a) the length of the induction time (b) the single pass removal efficiency determined during isoflurane degradation. $\left(\mathrm{C}_{0}=0.5 \mathrm{ppm} ; \mathrm{v}=1 \mathrm{~m} \mathrm{~s}^{-1} ; \mathrm{I}=4.5 \mathrm{~mW} \mathrm{~cm}^{-2}\right)$.

resulting in lower removal efficiencies [33]. This inhibition effect was also observed by Raillard et al. [33] when they studied the influence of RH $(0-30 \%)$ on the photocatalytic degradation of two ketones: acetone and 2-butanone. The experiments were performed in a 12-L Pyrex-glass batch reactor with $\mathrm{TiO}_{2}$ powder deposited on cellulose substrates. Similarly, Krichevskaya et al. [58] observed a decrease in the removal efficiency of acrylonitrile ( $40 \mathrm{ppm}$ ) when RH was increased from $0 \%$ to $66 \%$ in an annular reactor coated with Degussa (P25) $\mathrm{TiO}_{2}$ powder. These authors attributed the inhibition to the effect of competitive adsorption between the pollutant molecules and water.

For the induction period of isoflurane, the increase in the induction periods during increase in RH could also be attributed to the competition between isoflurane molecules and water molecules for adsorption onto active sites. As the RH increases, water molecules prevent isoflurane molecules from reacting with active species thus longer induction periods occur until sufficient concentration of $\mathrm{Cl}^{\circ}$ are formed to initiate the acceleration of the reaction.

At $20 \% \mathrm{RH}$ the moisture content at $20{ }^{\circ} \mathrm{C}$ is $4657 \mathrm{ppm}$. This increases to $11725 \mathrm{ppm}$ at $50 \% \mathrm{RH}$ and $18893 \mathrm{ppm}$ at $80 \% \mathrm{RH}$. These concentrations are quite high relative to the pollutant concentrations of $0.5 \mathrm{ppm}$ and $2 \mathrm{ppm}$ for isoflurane and acrylonitrile respectively. The percentage decrease in the single-pass removal efficiency from $20 \%$ to $50 \% \mathrm{RH}$ was $36 \%$ and $20 \%$ for acrylonitrile and isoflurane respectively whilst the percentage decrease from $50 \%$ to $80 \%$ was $18 \%$ and $14 \%$ for acrylonitrile and isoflurane respectively. This shows that although the degradation of both compounds is impeded by the increase in $\mathrm{RH}$, the influence was more pronounced when the $\mathrm{RH}$ was increased from $20 \%$ to $50 \%$ than from $50 \%$ to $80 \%$. This could be explained by the fact that at $50 \% \mathrm{RH}$ the surface already had abundant water and that increasing the concentration of water probably led to a saturation effect thus the removal efficiency was not drastically decreased when the RH was increased to $80 \%$.

It was also observed that acrylonitrile was more impacted by the presence of water vapor than isoflurane. Water molecules may form layers on the photocatalyst surface and therefore, in order to react, VOCs must first be absorbed into the water film and then penetrate towards the catalyst surface which also subsequently decrease the degradation efficiency $[59,60]$. The ability to do this could be related to the hydrophilic/hydrophobic properties of the VOC molecule. There are differing opinions given in the literature to explain this. Vildozo et al. [60] studied the influence of humidity on the degradation of 2-propanol and toluene using a photocatalyst, composed of non-woven paper coated with $20 \mathrm{~g} \mathrm{~m}^{-2}$ of $\mathrm{TiO}_{2}$. They observed that at high levels of humidity the degradation of toluene was more inhibited than that of 2 propanol. They explained that 2-propanol because of its higher solubility $\left(1000 \mathrm{~g} \mathrm{~L}^{-1}\right)$ is able to penetrate the layers of water and be adsorbed on the catalyst surface. On the contrary, toluene which has a lower solubility of $0.5 \mathrm{~g} \mathrm{~L}^{-1}$ might have difficulties to penetrate this layer. On the other hand, Raillard et al. [61] in studying the degradation of methyl ethyl ketone (MEK) on a photocatalyst made up of a film of $\mathrm{TiO}_{2}$ coated onto a glass plate observed that at higher relative humidity, the degradation rate of MEK was reduced. They stated that at high humidity level, the formation of a water layer is possible and that in addition to the competitive adsorption, because of its solubility, MEK may be dissolved in the water layer. Once dissolved into water, MEK is less willing to reach with the catalytic surface and active species because of a less rapid diffusion into water.

In this work, the degradation of acrylonitrile is more inhibited than isoflurane when the relative humidity is increased. Looking at their properties (Table 3), acrylonitrile is more hydrophilic (higher water solubility and lower $\log \mathrm{K}_{\mathrm{ow}}$ ) than isoflurane. In addition to this, acrylonitrile concentration (2 $\mathrm{ppm})$ is higher than that of isoflurane $(0.5 \mathrm{ppm})$. The influence of relative humidity could be impacted by the concentration of the compound in that the higher the concentration of the pollutant intensifies the negative effect of the relative humidity [62].

Relative humidity has a significant influence on the degradation of isoflurane and acrylonitrile. Under the experimental conditions studied, PCO performance during the degradation of both isoflurane and acrylonitrile is better at lower relative humidity. According to several national regulations, RH between $30 \%$ and $60 \%$ is recommended in ORs and at these levels water vapor exists in large excess compared to pollutant concentrations (usually ppb to several tens of ppm) and thus competitive adsorption which inhibits PCO performance can be deemed as the dominating process. Under this condition, it would be advisable not to operate above RH of $60 \%$.

\subsection{Presence of co-pollutants}

Single compound photocatalytic oxidation studies are convenient for understanding the kinetics of degradation of a compound but in the real case, the indoor air stream usually contains several contaminants.

Table 3

Water solubility and octanol-water partition coefficient ( $\left.\log \mathrm{K}_{\mathrm{ow}}\right)$ of acrylonitrile and isoflurane.

\begin{tabular}{lll}
\hline Compound & Log $\mathrm{K}_{\mathrm{ow}}$ & Water solubility $\left(\mathrm{g} . \mathrm{L}^{-1}\right)\left(25^{\circ} \mathrm{C}\right)$ \\
\hline Isoflurane & $2.1[63]$ & $2.5[63]$ \\
Acrylonitrile & $0.25[64]$ & $70[64]$
\end{tabular}


The OR is polluted by a variety of chemical pollutants such as waste anesthetic gases, sterilants and compounds present in surgical smoke. It is reasonable to assume that the coexistence of these compounds may have an influence on the degradation rate of isoflurane and acrylonitrile thus it would also be necessary to provide information on how the presence of co-pollutants may affect the degradation efficiency of the target compounds.

In this study nitrous oxide and acetic acid were chosen to study the effect of co-pollutants on the degradation efficiency of the target pollutants. Nitrous oxide is an anesthetic pollutant typically found in ORs. Acetic acid however is a derivative of peracetic acid (sterilant) and was chosen to represent peracetic acid as the latter was not stable enough to allow its use. In this work, a series of experiments conducted at different binary mixture configurations of nitrous oxide and acetic acid with acrylonitrile and isoflurane were made. As the co-pollutants may vary in concentration in an OR, the experiments were performed in two ways. Firstly degradation was performed at equi-molar concentrations of the co-pollutants and the target pollutants. Then the experiments were conducted with the co-pollutant at a higher concentration. Since the reference concentrations are different for isoflurane $(0.5 \mathrm{ppm})$ and acrylonitrile $(2 \mathrm{ppm})$, the higher concentration of the co-pollutant was chosen so that the molar ratios between the reference concentrations and co-pollutant concentration were the same for both isoflurane and acrylonitrile experiments. The compositions of these mixtures are described in Table 4.

Fig. 9 shows the experimental results for the binary mixtures compared to single compound experiments for acrylonitrile. The velocity and light intensity were fixed at $1 \mathrm{~m} \mathrm{~s}^{-1}$ and $4.5 \mathrm{~mW} \mathrm{~cm}^{-2}$ respectively. Acrylonitrile results showed that the single pass removal efficiencies were lower for binary mixtures than for the single component experiment. In the presence of the co-pollutants, the $\alpha$ decreased by $20 \%, 8 \%$ and $47 \%$ for mixtures A1, N1 and N2 respectively. For the equi-molar mixtures, acetic acid had a stronger inhibitory effect on acrylonitrile than nitrous oxide. It was also observed that the inhibition of acrylonitrile degradation was higher with increasing nitrous oxide concentrations.

Fig. 10 shows the experimental results for the binary mixtures compared to single compound experiments for isoflurane. The velocity and light intensity were fixed at $1 \mathrm{~m} \mathrm{~s}^{-1}$ and $4.5 \mathrm{~mW} \mathrm{~cm}^{-2}$ respectively. Isoflurane experiments showed that, in the presence of these co-pollutants the degradation of isoflurane was inhibited. The inhibitive effect is seen in the fact that the induction periods were increased whilst the removal efficiencies were decreased. The induction periods increased by $17 \%, 24 \%$ and $46 \%$ for mixtures A2, N3 and N4 respectively. The single-pass removal efficiencies decreased by $1 \%, 13 \%$ and $63 \%$ for mixtures A2, N3 and N4 respectively. Contrary to acrylonitrile, isoflurane single pass removal degradation was more negatively influenced by the presence of nitrous oxide than by acetic acid for the equimolar experiments. The inhibition of isoflurane degradation was higher with increasing nitrous oxide concentrations.

This trend of decreasing removal efficiencies was also been reported by Chen et al. [65] using an equi-molar ternary mixture of $0.5 \mathrm{ppm}$ toluene, ethyl acetate and ethanethiol. On the other hand, Chen et al. [66] observed no significant influence of the mixture effect on low concentrations $(0.1 \mathrm{ppm})$ of equi-molar binary or ternary mixtures of

Table 4

Binary mixture compositions.

\begin{tabular}{ll}
\hline Mixture Name & Composition \\
\hline A1 & $2 \mathrm{ppm}$ acrylonitrile $+2 \mathrm{ppm}$ acetic acid \\
N1 & $2 \mathrm{ppm}$ acrylonitrile $+2 \mathrm{ppm}$ nitrous oxide \\
N2 & $2 \mathrm{ppm}$ acrylonitrile $+25 \mathrm{ppm}$ nitrous oxide \\
A2 & $0.5 \mathrm{ppm}$ isoflurane $+0.5 \mathrm{ppm}$ acetic acid \\
N3 & $0.5 \mathrm{ppm}$ isoflurane $+0.5 \mathrm{ppm}$ nitrous oxide \\
N4 & $0.5 \mathrm{ppm}$ isoflurane $+6 \mathrm{ppm}$ nitrous oxide \\
\hline
\end{tabular}

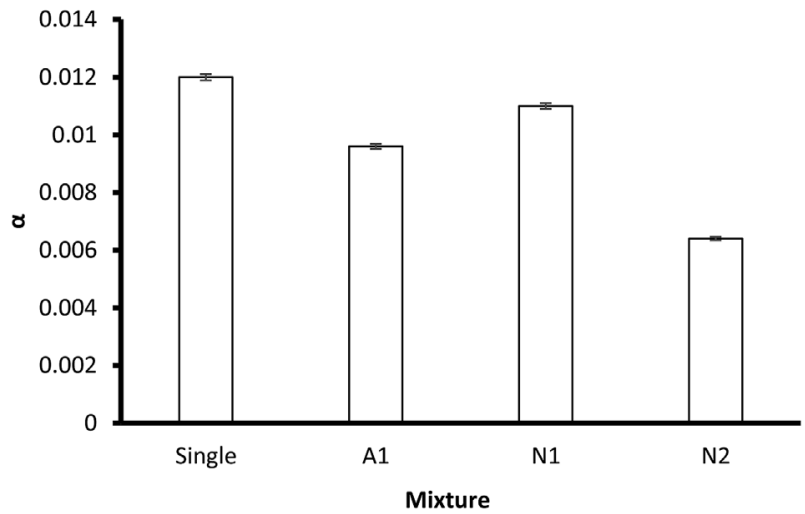

Fig. 9. Influence of presence of co-pollutants on the single pass removal efficiency determined during acrylonitrile degradation $\left(C_{O}=2 \mathrm{ppm} ; v=1 \mathrm{~m} \mathrm{~s}^{-1}\right.$; $I=4.5 \mathrm{~mW} \mathrm{~cm}^{-2} ; R H=50 \%$ ).

selected compounds but observed that in a 16 VOC mixture the interference effect among the selected VOCs became quite obvious, and their removal efficiencies were significantly decreased. The inhibitive effect observed by these authors was attributed to the possible competitive adsorption for active sites by the molecules. In this study, the decrease in the degradation of both isoflurane and acrylonitrile in the presence of the co-pollutants could also be explained by the possible competition for active sites.

Acetic acid is known to have a high adsorption affinity to $\mathrm{TiO}_{2}$ therefore it allows it to occupy more active sites and be degraded [67] and thus may have a higher competitive ability than the target compounds. For the isoflurane-acetic acid equi-molar mixture, it seemed that the inhibitory effect was more pronounced for the first phase than for the second phase as seen in Fig. $10 \mathrm{a}$ and b. The induction period increases from $130 \mathrm{~min}$ in the single compound degradation to $160 \mathrm{~min}$ in the equi-molar binary degradation but $\alpha$ remains at 0.0008 for both single compound and binary mixture experiments. Since acetic acid has a better adsorption affinity to the photocatalyst, it prevents enough isoflurane molecules from reaching the active sites thus delays the degradation mechanism by increasing the induction period. It can be assumed however that once acetic acid is no longer present, isoflurane degradation proceeds normally that could explain why the single-pass removal efficiency for the second phase was not significantly different from that obtained during single isoflurane degradation.

The experiments performed in mixture with $\mathrm{N}_{2} \mathrm{O}$ showed that it inhibited the degradation of both target compounds. Once the concentration of $\mathrm{N}_{2} \mathrm{O}$ was increased its inhibitory effect on the removal of the target compounds due to competitive adsorption unto active sites was intensified further decreasing the single-pass removal efficiencies of the target compounds.

\subsection{Presence of particles}

Aside gaseous pollutants, particulate matter is another type of pollutant that is found in indoor environments. Surgical smoke contains particles (tissue and microbial) which could be trapped by the photocatalyst media and subsequently their presence can affect the PCO of the target compounds. Surgical smoke is known to contain particles with diameters ranging from 0.35 to $6.5 \mu \mathrm{m}$ [47]. To simulate the presence of particles the photocatalytic surface was loaded with rice particles at a rate of $0.002 \mathrm{~g} \mathrm{~m}^{-2}$. The particle diameter range was $0.25-10.5 \mu \mathrm{m}$ thus was a good representation of particles that could be collected on the photocatalytic media in an OR.

Fig. 11 shows the results for acrylonitrile degradation in the absence and presence of particles. The velocity, light intensity and concentration were fixed at $1 \mathrm{~m} \mathrm{~s}^{-1}$ and $4.5 \mathrm{~mW} \mathrm{~cm}^{-2}$ and $2 \mathrm{ppm}$ respectively. It can be observed that $\alpha$ decreases by $22.5 \%$ when particles are present 

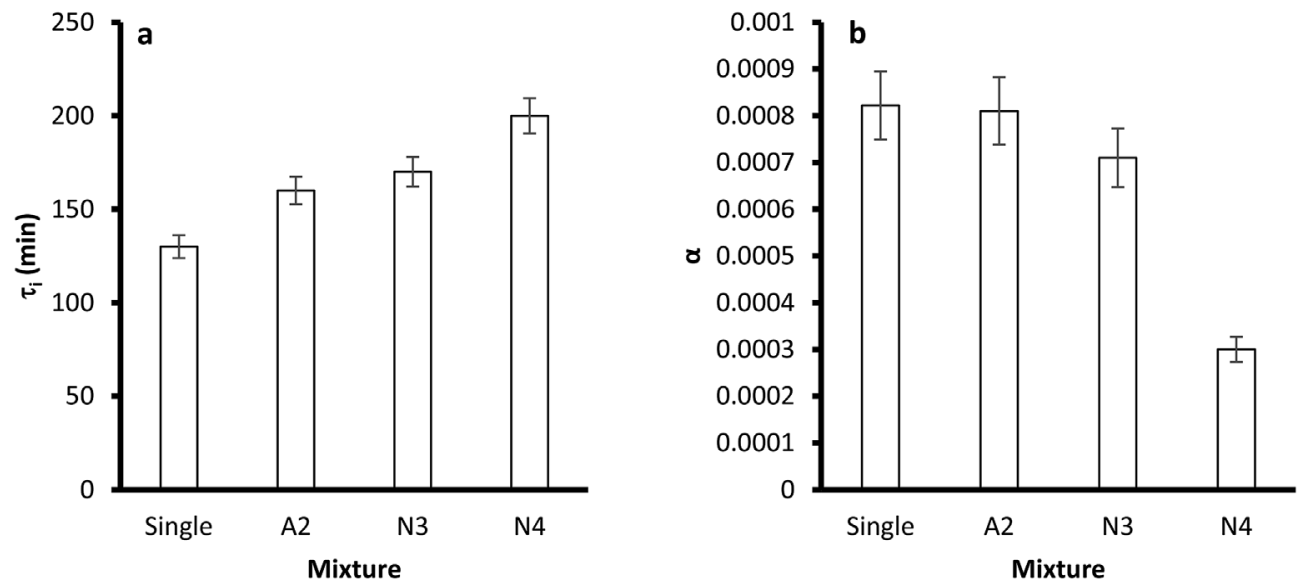

Fig. 10. Influence of presence of co-pollutants on (a) the length of the induction time (b) the single pass removal efficiency determined during isoflurane degradation $\left(C_{0}=0.5 \mathrm{ppm} ; v=1 \mathrm{~m} \mathrm{~s}^{-1} ; I=4.5 \mathrm{~mW} \mathrm{~cm}^{-2} ; R H=50 \%\right)$.

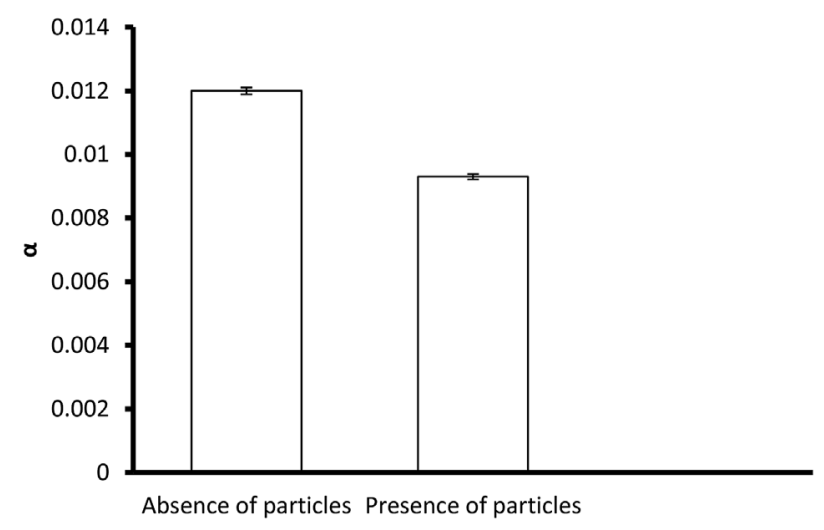

Fig. 11. Influence of the presence of particles on the single pass removal efficiency determined during acrylonitrile degradation $\left(C_{0}=2 \mathrm{ppm} ; v=1 \mathrm{~m} \mathrm{~s}^{-1}\right.$; $I=4.5 \mathrm{~mW} \mathrm{~cm}^{-2} ; R H=50 \%$ ).

on the photocatalytic media.

The results for isoflurane degradation are presented in Fig. 12. For these experiments, the velocity, light intensity and concentration were fixed at $1 \mathrm{~m} \mathrm{~s}^{-1}$ and $4.5 \mathrm{~mW} \mathrm{~cm}^{-2}$ and $0.5 \mathrm{ppm}$ respectively. From the figure, it can be observed that $\alpha$ decreases by $15 \%$ whilst the induction time increases by $25 \%$ when particles are present on the photocatalytic media.

Under the experimental conditions employed, the degradation of both compounds is impeded by the presence of particles with the same

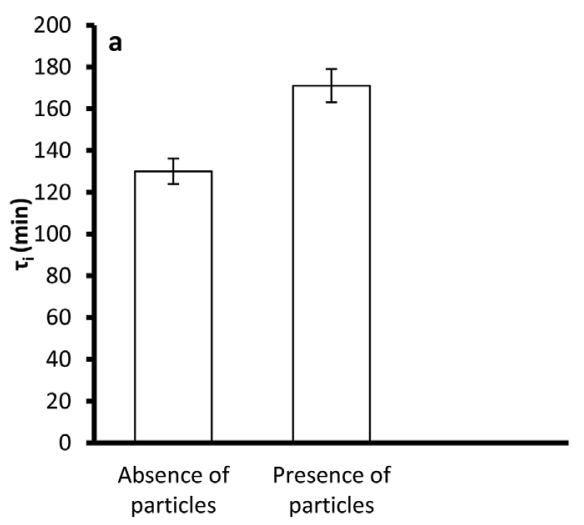

order of magnitude. The trend of decreasing removal efficiencies has been reported by Park et al. [68]. They studied the degradation of toluene in a single-pass PCO reactor using a non woven-fabric coated with $\mathrm{TiO}_{2}$. They observed that when air containing particles was introduced into the photocatalytic reactor, toluene removal efficiency was decreased. They explained this by two hypotheses. First, the particles could hide the active sites which could in turn block these sites for adsorption by the target compounds effectively reducing their degradation. Secondly, the particles could promote a "screening effect" thereby reducing the amount of light reaching the catalyst surface resulting in slower production of active species. Consequently, the progress of the degradation could be impeded.

In this work, the inhibition of the degradation of isoflurane and acrylonitrile could be due to the fact that the particles block the active sites preventing the molecules from adsorbing and being degraded. Secondly the particles could also screen the light intensity thereby reducing the amount of light reaching the catalyst surface. Conclusively, it would be recommended that for a PCO unit, filters should be placed upstream of the photocatalytic media to reduce the particle load reaching the photocatalytic media in order to improve the PCO performance.

\subsection{Identification of potential by-products}

By-product formation was investigated in a previous part of this work under standard humid air condition $(\mathrm{RH}=50 \%)$ in function of process parameters and without co-pollutants [46,52]. For isoflurane,

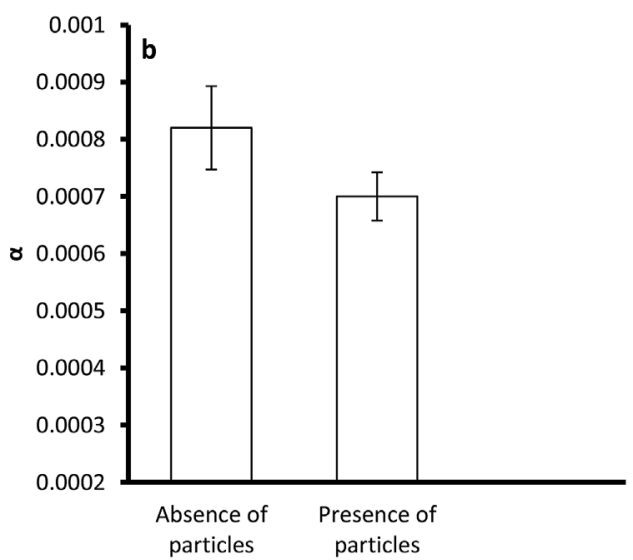

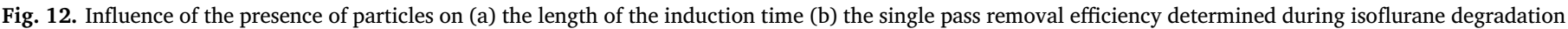
$\left(C_{O}=0.5 \mathrm{ppm} ; v=1 \mathrm{~m} \mathrm{~s}^{-1} ; I=4.5 \mathrm{~mW} \mathrm{~cm}^{-2} ; R H=50 \%\right)$. 
some halogenated and oxygenated by-products were identified but at low concentrations $(<0.04 \mathrm{ppm})$ and no significant risks based on a calculated Health-Related Index (HRI) [46]. For acrylonitrile, under initial concentrations ranging from 0.5 to $10 \mathrm{ppm}$ and with sampling and analytical devices used, no by-products were identified. However, complete mineralization under longer irradiation times signified the possible removal of intermediates [52]. In this work however, under the studied environmental parameters no by-products were identified.

\section{Conclusion}

In this work, acrylonitrile and isoflurane, two pollutants that are present in ORs air were chosen as representative compounds to investigate the performance of PCO by studying the influence of three environmental parameters. The experiments were performed in a closed loop laboratory reactor to evaluate the efficiency of degradation by PCO. The use of a model developed by Dumont and Héquet enables the calculation of one performance indicator (the single pass removal efficiency) for acrylonitrile and two indicators (single pass removal efficiency and induction period) for isoflurane. The qualitative descriptor enabled the study of the influence of the relative humidity, the presence of co-pollutants and the presence of particles on the degradation process.

The results showed that although the pollutants belonged to different chemical classes, the influence of the parameters on their degradation was similar. Relative humidity has a significant influence on the degradation of isoflurane and acrylonitrile. Under the experimental conditions studied, PCO performance during the degradation of both isoflurane and acrylonitrile is better at lower relative humidity. According to several national regulations, $\mathrm{RH}$ between $30 \%$ and $60 \%$ is recommended in ORs and at these levels water vapor exists in large excess compared to pollutant concentrations (usually ppb to several tens of ppm) and thus competitive adsorption which inhibits PCO performance can be deemed as the dominating process. Under this condition, it would be advisable not to operate above RH of $60 \%$. Under the experimental conditions employed in this study, it can be concluded that PCO performance during the degradation of the target pollutants could be inhibited by the presence of co-pollutants due to competitive adsorption for active sites. Additionally the higher the concentration of the co-pollutant compared to the target compound the higher the inhibition effect. The concentrations of co-pollutants present in the OR air vary depending on the activities and thus cannot be controlled. However in order to improve the PCO performance it would be recommended that several photocatalytic banks (photocatalytic media and UV lamps) are installed in the PCO unit in order to maximize the removal of these pollutants and to ensure higher removal efficiency. The presence of particles inhibited the degradation of the two compounds because they blocked the active sites. Since the production of particles in the OR cannot be avoided, it would be recommended that for a PCO unit, filters should be placed upstream of the photocatalytic media to reduce the particle load reaching the photocatalytic media in order to improve the PCO performance.

In conclusion, PCO could be used as a treatment technique to improve air quality in the OR as the results show that it can degrade OR pollutants like isoflurane and acrylonitrile. However as also shown, a single-pass is not enough to remove a substantial amount of these pollutants from the incoming air. It would be recommended that for a treatment device, several photocatalytic banks plus an addition of filters are used in order to maximize the removal of the target pollutants as well as their intermediates.

\section{Acknowledgements}

The authors would like to express their gratitude to ATA Medical and IMT Atlantique for their financial support and also to Eric Chevrel, Patrick Brion, Francois-Xavier Blanchet, Yvan Gouriou and Katell
Chaillou for their invaluable technical assistance and to Eric Dumont for his help with the modeling.

\section{References}

[1] M. Leung, A.H.S. Chan, Control and management of hospital indoor air quality, Med. Sci. Mon. Int. Med. J. Exp. Clin. Res. 12 (2006) SR17-23 http://www.ncbi. nlm.nih.gov/pubmed/16501436 (accessed March 20, 2017).

[2] J.P. Gangneux, S. Belaz, G. Barbe, O. Blanchard, F. Mercier, P.Y. Donnio, M. Guillaso, A. Rivier, P. Le Can, A. Florentin, E. Baures, Concomitant determination of indoor air microbiological and chemical contamination for a global approach of air quality in hospitals, Mycoses 60 (2017) 122-123 https://hal-univ rennes1.archives-ouvertes.fr/hal-01632369/, Accessed date: 13 March 2018.

[3] C.A. Balaras, E. Dascalaki, A. Gaglia, HVAC and indoor thermal conditions in hospital operating rooms, Energy Build. 39 (2007) 454-470, https://doi.org/10. 1016/j.enbuild.2006.09.004.

[4] E.G. Dascalaki, A. Lagoudi, C.A. Balaras, A.G. Gaglia, Air quality in hospital operating rooms, Build. Environ. 43 (2008) 1945-1952, https://doi.org/10.1016/j. buildenv.2007.11.015.

[5] W.L. Barrett, S.M. Garber, Surgical smoke: a review of the literature, Surg. Endosc Other Interv. Tech. 17 (2003) 979-987, https://doi.org/10.1007/s00464-0028584-5.

[6] C. Byhahn, H.J. Wilke, K. Westphal, Occupational exposure to volatile anaesthetics epidemiology and approaches to reducing the problem, CNS Drugs 15 (2001) 197-215, https://doi.org/10.2165/00023210-200115030-00004.

[7] M.M. Chaoul, J.R.C. Braz, L.M.C. Lucio, M.A. Golim, L.G. Braz, M.G. Braz, Does occupational exposure to anesthetic gases lead to increase of pro-inflammatory cytokines? Inflamm. Res. 64 (2015) 939-942, https://doi.org/10.1007/s00011015-0881-2.

[8] D. Gupta, G. Mckelvey, E. Kaminski, M.M. Zestos, Does exposure to inhalation anesthesia gases change the ratio of X-bearing sperms and Y-bearing Sperms? A worth exploring project into an uncharted domain, Med. Hypotheses 94 (2016) 68-73, https://doi.org/10.1016/j.mehy.2016.07.002.

[9] T. Choosong, J. Pakpirom, K. Sakolprakaikit, C. Punlamai, A. Jitjamnong, Assessment of waste anesthetic gases exposure among nurse anesthetists in a university hospital, Songklanagarind Med. Journal 33 (2015) 139-152.

[10] M.J. Checkai, Risk Assessment for Occupational Exposure to Isoflurane in Pharmaceutical Research and Veterinary Facilities in San Diego, Thesis Health and Human Services, California, 2014.

[11] J.K.-M. Fan, F.S.-Y. Chan, K.-M. Chu, Surgical smoke, Asian J. Surg. 32 (2009) 253-257, https://doi.org/10.1016/S1015-9584(09)60403-6.

[12] D.S. Hill, J.K. O'Neill, R.J. Powell, D.W. Oliver, Surgical smoke - a health hazard in the operating theatre: a study to quantify exposure and a survey of the use of smoke extractor systems in UK plastic surgery units, J. Plast. Reconstr. Aesthetic Surg. JPRAS. 65 (2012) 911-916, https://doi.org/10.1016/j.bjps.2012.02.012.

[13] N. Mowbray, J. Ansell, N. Warren, P. Wall, J. Torkington, Is surgical smoke harmful to theater staff? a systematic review, Surg. Endosc. 27 (2013) 3100-3107, https:/ doi.org/10.1007/s00464-013-2940-5.

[14] J. Hobbhahn, K. Hoerauf, G. Wiesner, K. Schrögendorfer, K. Taeger, Waste gas exposure during desflurane and isoflurane anaesthesia, Acta Anaesthesiol. Scand. 42 (1998) 864-867 http://www.ncbi.nlm.nih.gov/pubmed/9698966, Accessed date: 31 October 2017

[15] A. Neisi, M. Albooghobeish, S. Geravandi, M.J. Mohammadi, M. Torabpour, B. Hashemzadeh, Association of anesthetic toxic isoflurane gases of the indoor air of operating room, Ahvaz, Iran during 2016, Toxin Rev. 36 (2017) 141-146, https:// doi.org/10.1080/15569543.2016.1252931.

[16] Y.J. Chung, S.K. Lee, S.H. Han, C. Zhao, M.K. Kim, S.C. Park, J.K. Park, Harmful gases including carcinogens produced during transurethral resection of the prostate and vaporization, Int. J. Urol. 17 (2010) 944-949, https://doi.org/10.1111/j.1442 2042.2010.02636.x.

[17] ASHRAE, ASHRAE 170-2017-ventilation of health care facilities, https://www. techstreet.com/ashrae/standards/ashrae-170-2017?product_id = 1999079\&ashrae auth_token $=12$ ce7b1d-2e2e-472b-b689-8065208f2e36, (2017), Accessed date: 18 April 2018

[18] AFNOR, NF S90-351 - health care institutions - controlled environment areas - requirements for airborne contamination control, https://www.boutique.afnor.org/ norme/nf-s90-351/etablissements-de-sante-zones-a-environnement-maitriseexigences-relatives-a-la-maitrise-de-la-contamination-aeroportee/article/809391 fa168416, (2013) (accessed April 18, 2018).

[19] P.T.J. Scheepers, L. Van Wel, G. Beckmann, R.B.M. Anzion, Chemical characterization of the indoor air quality of a university hospital: penetration of outdoor air pollutants, Int. J. Environ. Res. Public Health 14 (2017), https://doi.org/10.3390/ ijerph14050497.

[20] L. Zhong, J.J. Brancho, S. Batterman, B.M. Bartlett, C. Godwin, Experimental and modeling study of visible light responsive photocatalytic oxidation (PCO) materials for toluene degradation, Appl. Catal. B Environ. 216 (2017) 122-132, https://doi. org/10.1016/J.APCATB.2017.05.047.

[21] V. Bergeron, G. Reboux, J.L. Poirot, N. Laudinet, Decreasing airborne contamination levels in high-risk hospital areas using a novel mobile air-treatment unit, Infect. Control Hosp. Epidemiol. 28 (2007) 1181-1186, https://doi.org/10.1086/520733.

[22] T.S. Le, T.H. Dao, D.C. Nguyen, H.C. Nguyen, I.L. Balikhin, Air purification equipment combining a filter coated by silver nanoparticles with a nano-TiO 2 photocatalyst for use in hospitals, Adv. Nat. Sci. Nanosci. Nanotechnol. 6 (2015) 015016, https://doi.org/10.1088/2043-6262/6/1/015016. 
[23] M. Perraud, M.C. Nicolle, E. Chiarello, F. Tissot Guerraz, J.C. Cetre, M. Sepetjan, Air filtration and prevention of aspergillary pneumopathies. Preliminary comparative study of two mobile units for bacteriological air purification with recycling, Nouv Rev. Fr. Hematol. 34 (1992) 295-299.

[24] R.A. Rosenbaum, J.S. Benyo, R.E. O'Connor, B.A. Passarello, D.R. Williams, B.D. Humphrey, R.W. Ross, J.M. Berry, J.G. Krebs, Use of a portable forced air system to convert existing hospital space into a mass casualty isolation area, Ann. Emerg. Med. 44 (2004) 628-634, https://doi.org/10.1016/j.annemergmed.2004. 03.012 .

[25] T. Schoenleber, H. Gbaguidi Haore, L. Jeunet, D. Talon, Évaluation d'un dispositif mobile de décontamination pour la maîtrise de l'air au bloc opératoire, Hygie 15 (2007) 158-164.

[26] L. Zhong, F. Haghighat, Photocatalytic air cleaners and materials technologies abilities and limitations, Build. Environ. 91 (2015) 191-203, https://doi.org/10. 1016/J.BUILDENV.2015.01.033.

[27] J. Zhao, X. Yang, Photocatalytic oxidation for indoor air purification: a literature review, Build. Environ. 38 (2003) 645-654, https://doi.org/10.1016/S03601323(02)00212-3.

[28] H. Destaillats, M. Sleiman, D.P. Sullivan, C. Jacquiod, J. Sablayrolles, L. Molins, Key parameters influencing the performance of photocatalytic oxidation (PCO) air purification under realistic indoor conditions, Appl. Catal. B Environ. 128 (2012) 159-170, https://doi.org/10.1016/j.apcatb.2012.03.014.

[29] Y. Boyjoo, H. Sun, J. Liu, V.K. Pareek, S. Wang, A review on photocatalysis for air treatment: from catalyst development to reactor design, Chem. Eng. J. 310 (2017) 537-559, https://doi.org/10.1016/J.CEJ.2016.06.090.

[30] H. Ren, P. Koshy, W.-F. Chen, S. Qi, C.C. Sorrell, Photocatalytic materials and technologies for air purification, J. Hazard Mater. 325 (2017) 340-366, https://doi. org/10.1016/j.jhazmat.2016.08.072.

[31] J. Mo, Y. Zhang, R. Yang, Novel insight into VOC removal performance of photocatalytic oxidation reactors, Indoor Air 15 (2005) 291-300, https://doi.org/10. 1111/j.1600-0668.2005.00374.x.

[32] D. Farhanian, F. Haghighat, C.-S.S. Lee, N. Lakdawala, Impact of design parameters on the performance of ultraviolet photocatalytic oxidation air cleaner, Build. Environ. 66 (2013) 148-157.

[33] C. Raillard, V. Héquet, P. Le Cloirec, J. Legrand, Kinetic study of ketones photocatalytic oxidation in gas phase using TiO2-containing paper: effect of water vapor, J. Photochem. Photobiol. A Chem. 163 (2004) 425-431.

[34] M. Sleiman, P. Conchon, C. Ferronato, J.-M. Chovelon, Photocatalytic oxidation of toluene at indoor air levels (ppbv): towards a better assessment of conversion, reaction intermediates and mineralization, Appl. Catal. B Environ. 86 (2009) 159-165.

[35] C.H.H. Ao, S.C.C. Lee, J.Z.Z. Yu, J.H.H. Xu, Photodegradation of formaldehyde by photocatalyst TiO2: effects on the presences of NO, SO2 and VOCs, Appl. Catal. B Environ. 54 (2004) 41-50.

[36] X. Ye, D. Chen, J. Gossage, K. Li, Photocatalytic oxidation of aldehydes: byproduct identification and reaction pathway, J. Photochem. Photobiol. A Chem. 183 (2006) 35-40, https://doi.org/10.1016/j.jphotochem.2006.02.019.

[37] W. Chen, J.J. Zhang, Photocatalytic oxidation of multi-component systems - an investigation using toluene/ethylbenzene, octane/decane/dodecane and formaldehyde/acetaldehyde, J. Adv. Oxid. Technol. 11 (2016) 163-173, https://doi. org/10.1515/jaots-2008-0123.

[38] Q.L. Yu, H.J.H. Brouwers, Indoor air purification using heterogeneous photocatalytic oxidation. Part I: experimental study, Appl. Catal. B Environ. 92 (2009) 454-461, https://doi.org/10.1016/j.apcatb.2009.09.004.

[39] P. Pichat, Some views about indoor air photocatalytic treatment using TiO2: conceptualization of humidity effects, active oxygen species, problem of C1-C3 carbonyl pollutants, Appl. Catal. B Environ. 99 (2010) 428-434, https://doi.org/10 1016/J.APCATB.2010.07.022.

[40] R. Dillert, J. Stötzner, A. Engel, D.W. Bahnemann, Influence of inlet concentration and light intensity on the photocatalytic oxidation of nitrogen(II) oxide at the surface of Aeroxide ${ }^{\circledR}$ TiO2 P25, J. Hazard Mater. 211-212 (2012) 240-246, https:// doi.org/10.1016/J.JHAZMAT.2011.11.041.

[41] E. Dumont, V. Héquet, Determination of the clean air delivery rate (CADR) of photocatalytic oxidation (PCO) purifiers for indoor air pollutants using a closedloop reactor. Part I: theoretical considerations, Molecules (2017) 22, https://doi. org $/ 10.3390 /$ molecules 22030407.

[42] V. Héquet, C. Raillard, O. Debono, F. Thévenet, N. Locoge, L. Le Coq, Photocatalytic oxidation of VOCs at ppb level using a closed-loop reactor: the mixture effect, Appl. Catal. B Environ. (2017), https://doi.org/10.1016/j.apcatb.2017.12.041.

[43] F. Batault, V. Héquet, C. Raillard, F. Thévenet, N. Locoge, L. Le Coq, How chemical and physical mechanisms enable the influence of the operating conditions in a photocatalytic indoor air treatment device to be modeled, Chem. Eng. J. 307 (2017) 766-775, https://doi.org/10.1016/j.cej.2016.08.118.

[44] C. Raillard, A. Maudhuit, V. Héquet, L. Le Coq, J. Sablayrolles, L. Molins, Use of experimental designs to establish a kinetic law for a gas phase photocatalytic process, Int. J. Chem. React. Eng. 12 (2014) 113, https://doi.org/10.1515/ijcre-20140012.

[45] A. Maudhuit, C. Raillard, V. Héquet, L. Le Coq, J. Sablayrolles, L. Molins, Adsorption phenomena in photocatalytic reactions: the case of toluene, acetone and heptane, Chem. Eng. J. 170 (2011) 464-470, https://doi.org/10.1016/j.cej.2011. 02.040 .

[46] H.E. Whyte, C. Raillard, A. Subrenat, V. Hequet, Photocatalytic oxidation of isoflurane, an anesthetic gas: the influence of operating parameters, Chem. Eng. J. (2018), https://doi.org/10.1016/j.cej.2018.07.059.

[47] K.J. Weld, S. Dryer, C.D. Ames, K. Cho, C. Hogan, M. Lee, P. Biswas, J. Landman, Analysis of surgical smoke produced by various energy-based instruments and effect on laparoscopic visibility, J. Endourol. 21 (2007) 347-351, https://doi.org/10. 1089/end.2006.9994.

[48] O. Debono, V. Héquet, L. Le Coq, N. Locoge, F. Thévenet, VOC ternary mixture effect on ppb level photocatalytic oxidation: removal kinetic, reaction intermediate and mineralization, Appl. Catal. B Environ. 218 (2017) 359-369, https://doi.org/ 10.1016/j.apcatb.2017.06.070

[49] M. Hegedüs, A. Dombi, Comparative study of heterogeneous photocatalytic decomposition of tetrachloroethene and trichloroethene in the gas phase, Appl. Catal. Gen. 271 (2004) 177-184, https://doi.org/10.1016/j.apcata.2004.02.057.

[50] G. Li Puma, I. Salvadó-Estivill, T.N. Obee, S.O. Hay, Kinetics rate model of the photocatalytic oxidation of trichloroethylene in air over TiO2 thin films, Separ. Purif. Technol. 67 (2009) 226-232, https://doi.org/10.1016/J.SEPPUR.2009.03. 011.

[51] W.A. Jacoby, M.R. Nimlos, D.M. Blake, R.D. Noble, C.A. Koval, Products, intermediates, mass balances, and reaction pathways for the oxidation of trichloroethylene in air via heterogeneous photocatalysis, Environ. Sci. Technol. 28 (1994) 1661-1668, https://doi.org/10.1021/es00058a018.

[52] H.E. Whyte, Evaluation of the performance of photocatalytic systems for the treatment of indoor air in medical environments, IMT Atlantique, 2018, http:// www theses fr/2018IMTA0112.

[53] A.H. Mamaghani, F. Haghighat, C.-S.S. Lee, Photocatalytic oxidation technology for indoor environment air purification: the state-of-the-art, Appl. Catal. B Environ. 203 (2017) 247-269, https://doi.org/10.1016/J.APCATB.2016.10.037.

[54] J. Mo, Y. Zhang, Q. Xu, J.J. Lamson, R. Zhao, Photocatalytic purification of volatile organic compounds in indoor air: a literature review, Atmos. Environ. 43 (2009) 2229-2246.

[55] T. Tytgat, B. Hauchecorne, A.M. Abakumov, M. Smits, S.W. Verbruggen, S. Lenaerts, Photocatalytic process optimisation for ethylene oxidation, Chem. Eng. J. 209 (2012) 494-500, https://doi.org/10.1016/J.CEJ.2012.08.032.

[56] L. Zhong, F. Haghighat, P. Blondeau, J. Kozinski, Modeling and physical interpretation of photocatalytic oxidation efficiency in indoor air applications, Build. Environ. 45 (2010) 2689-2697.

[57] J. Mo, Y. Zhang, Q. Xu, Effect of water vapor on the by-products and decomposition rate of ppb-level toluene by photocatalytic oxidation, Appl. Catal. B Environ. 132-133 (2013) 212-218, https://doi.org/10.1016/J.APCATB.2012.12.001.

[58] M. Krichevskaya, S. Jõks, A. Kachina, S. Preis, Gas-phase photocatalytic oxidation of acrylonitrile, Photochem. Photobiol. Sci. 8 (2009) 600, https://doi.org/10.1039/ b817063k.

[59] L. Zhang, W.A. Anderson, S. Sawell, C. Moralejo, Mechanistic analysis on the influence of humidity on photocatalytic decomposition of gas-phase chlorobenzene, Chemosphere 68 (2007) 546-553, https://doi.org/10.1016/J.CHEMOSPHERE. 2006.12.056.

[60] D. Vildozo, R. Portela, C. Ferronato, J.-M. Chovelon, Photocatalytic oxidation of 2 propanol/toluene binary mixtures at indoor air concentration levels, Appl. Catal. B Environ. 107 (2011) 347-354, https://doi.org/10.1016/J.APCATB.2011.07.035.

[61] C. Raillard, V. Héquet, P. Le Cloirec, J. Legrand, TiO2 coating types influencing the role of water vapor on the photocatalytic oxidation of methyl ethyl ketone in the gas phase, Appl. Catal. B Environ. 59 (2005) 213-220, https://doi.org/10.1016/J. APCATB.2005.02.011

[62] A.A. Assadi, A. Bouzaza, D. Wolbert, Photocatalytic oxidation of trimethylamine and isovaleraldehyde in an annular reactor: influence of the mass transfer and the relative humidity, J. Photochem. Photobiol. A Chem. 236 (2012) 61-69, https:// doi.org/10.1016/J.JPHOTOCHEM.2012.03.020.

[63] National Center for Biotechnology Information, Acrylonitrile, PubChem compd. Database (n.d.), https://pubchem.ncbi.nlm.nih.gov/compound/7855, Accessed date: 31 July 2018.

[64] National Center for Biotechnology Information, Isoflurane, PubChem Compd. Database (n.d.), https://pubchem.ncbi.nlm.nih.gov/compound/isoflurane\# section $=$ Top , Accessed date: 31 July 2018.

[65] J. Chen, G. Li, Z. He, T. An, Adsorption and degradation of model volatile organic compounds by a combined titania-montmorillonite-silica photocatalyst, J. Hazard Mater. 190 (2011) 416-423, https://doi.org/10.1016/j.jhazmat.2011.03.064.

[66] W. Chen, J. Zhang, Z. Zhang, UV-PCO device for indoor VOCs removal: investigation on multiple compounds effect, Indoor Air (2005), https://www.isiaq.org/docs/ PDFs/3981.pdf , Accessed date: 28 May 2018.

[67] F. Batault, F. Thevenet, V. Hequet, C. Raillard, L. Le Coq, N. Locoge, Acetaldehyde and acetic acid adsorption on TiO2 under dry and humid conditions, Chem. Eng. J. 264 (2015) 197-210, https://doi.org/10.1016/J.CEJ.2014.10.089.

[68] O. Park, C.S. Kim, H.H. Cho, Development of a photoreactive fabric filter for simultaneous removal of VOCs and fine particles, Kor. J. Chem. Eng. 23 (2006) 194-198, https://doi.org/10.1007/BF02705715. 